\title{
Optimization Model for Allocation of Hospital Beds Under the Trend of Aging Population
}

\author{
Yuze "Edward" Gu ${ }^{1, a^{*}}$, Qianwen "Chloe" Luo 2 , b, \\ ${ }^{1}$ Springside Chestnut Hill Academy, PA, USA \\ ${ }^{2}$ St. Andrews School, DE, USA \\ ygu@sch.org, bluelionsluo579@gmail.com \\ ${ }^{*}$ Corresponding author
}

Keywords: Hospital bed allocation, Ageing issues, Optimization model

\begin{abstract}
Currently, there is an increasing trend for the demand of hospital beds. Due to the increasing cost of healthcare services and the aging of population, the hospitals need to pay more attention to integration of the resource management and hospital bed allocation. In this study, Gini coefficients and Lorenz Curve are used to predict the aging of population, which helps to build up the supply and demand curve of the hospital beds in the long time run. The Erlang Loss Formula is used to analyze the patient flow in the hospitals of the region with the different situations of area and the need for medical care. The Logistic model is used to predict the future outcome of allocation of hospital beds. In the next step, the optimization model is proceeded to get the optimal arrangement of hospital bed allocation.
\end{abstract}

\section{Introduction}

As human diseases are increasingly becoming complex, the need for specialist medical consultation along with creative ways to allocate resources such as hospital beds is essential. Human Resources are seen as one of the most costly and complex components that are now facing the health care industry. For instance, poor management would result in inequitable health results fort rural population, high risk, and remote area communities. However, the most vulnerable populations, such as the aging population might be the most affected if the resources are not effectively distributed ([6]). As much as emerging diseases and complex clinical conditions warrant greater requirement for specialized are. The distribution and quantity of medical resources are crucial problems worth noting. For example, hospital beds have been a major problem. In contemporary society, there is a growing trend for the demand for hospital beds. Because of the increasing healthcare services cost and the increment in the number of the aging population, it is imperative for healthcare services and facilities to concentrate on integrating hospital bed allocation and resource management ([9]). The employment of hospital beds should be taken into account as one of the primary elements of the public health care system.

The concept of hospital allocation has raised a growing number of debate among economists for several years. There is a need to exploit and develop an efficient and practical technique that can be employed in the allocation of clinical beds ([6]). When hospitals do not have enough beds, there have been practical situations where patients have to suffer or hare beds. For this reason, using beds relevantly and saving resources is of importance for the advancement of the health care industry and the progress of the economy ([9]). A literature review and analysis of previous studies on the creation of the optimization model that can be employed in dealing with this problem should be examined so as to identify any potential gaps and how to improve on the current situation.

\section{Background Information}

With the gradual aging population coupled with the current deficits in hospital beds in specific developed locations, there is a need to excavate the seriousness of this matter with the help of optimization and prediction models. Efficient hospital bed allocation in a certain health facility 
requires not only demand information, such as hospital expansion or patient complexity, but it also requires the willingness of the facility and the government to invest and allocate a certain amount to unanticipated sites. As much as this issue has been a common happening in the public health care system, evidence and proof revolving around how to promote an efficient hospital bed allocation have been lacking for decades ([5]). The world is aging. In several countries, the changes in the population age mix require an increased demand for resources and expensive health care. In the contemporary world, there has been an occurrence of moral conflicts as a result of resource allocation for health. With the growing magnitude of limited resources and health inequalities, we need to develop a framework and optimization model that will ensure that the priorities of the management when allocating this resources among the aging population are based on the impact programs, policies, actions on health, projects and knowledge of the aging population's health situation ([6]). The actors in the health industry that are involved in the allocation of resources, such as beds, especially the physicians and the managers are expected to make informed decisions based on the scarcity of real resources and the baseline that it is morally right to allocate them in such issues. To deal with this situations, there is a need to develop an optimization model that can reflect the clinical complexity, diversity, and hospital bed needs for the aging population in a healthcare setting.

\subsection{Literature Review}

According to [9], physician's engagement is a concept that is commonly employed for ensuring that physicians can collaborate with other healthcare stakeholders to leverage the quality of care and the experience of patients on a continuous basis. It is determined by the increase in the level of satisfaction and loyalty to their hospital facilities, quality improvement and alignment of key costs ([5]). In this case, the physicians are engaged under such circumstances as those that are committed to ensuring that the mission of their facility is achieved and are willing to assist the health care organization when needs. Apparently, such commitment is crucial to the overall performance of the company. To develop a proper hospital bed optimization model, we need to first ensure the physicians and healthcare specialists are willing to attend to more paging patients that are assigned to them.

Many healthcare facilities have been successful in using shared resources within a certain hospital network or reallocating resources within a merged network to deal with the challenge of limited resources. [9] conducted a research on the results of acquisitions and mergers in healthcare facilities and established that the rates of mergers are related to cost savings when it comes to lower occupancy facilities ([8]). On the other hand, demonstrated that the merger of four branches played a crucial role in reducing the costs of operations by ensuring that the occupancy rates are curbed. Moreover, [5] postulate that the placement models are one of the prominent for provision of sanitation services and a growing number of studies have purposed to curb costs of traveling such as those conducted by ([7]).

Efficient resource allocation such as hospital beds across the healthcare facility in a network needs not only information demand, but it is possible to apply linear programming in developing an optimization model that can be used to allocate resources such as beds, dentists, doctors to fit the requirements of the hospital as well as in disaster or emergency situations. For instance, [9] in his study attempted to allocate dentists, physicians and nurses by establishing mobile health services while [10] conducted a research on the allocation of transport facilities in a case of emergency using linear programming. However, it is imperative to note that there has been no research that has been able to develop an optimization model on the allocation of hospital beds among the aging population.

[6] performed a four-rounded modified Survey that took into account all the hospital executives to help in the identification of potential determinants of resource allocations among the aging populations and some of the factors that might influence decisions about their allocation based on the demand areas. The author developed a questionnaire based on 40 primary areas identified from published literature and reviewed by private and public experts to guarantee face validity. The findings of this research exemplified the employment of the Linear Programing technique in the optimization of resource allocation in a healthcare facility and large hospital network. A number of research works have employed linear programming in resource allocation, but they only concentrated 
on mapping the requirements of the patients based on the available resources. Yet, heuristic principles should be taken into account when making decisions since not only mathematical models can be important in developing an optimizing model for allocation of resources.

\section{Methodology and Modeling}

\subsection{Problem Statement}

Alarmed by the gradual aging of the population and the current hospital bed deficits in certain developed areas, we are determined to excavate the seriousness of this worldly issue, by using prediction and optimization models. In other words, we want to find the answers for below questions: what caused the problem, how serious is it, and why? What we are trying to do is to seek out how the population aging drags down the stagnating economy, which in turn worsens the hospital bed deficits, and eventually find a feasible resolution to make the current hospital bed arrangement system allocatively efficient. We are using the data for hospital beds throughout different states in the United States of America as a benchmark to reflect and resolve the issue.

\subsection{Assumptions}

- People's incentive to maximize their profit and utility holds true in the experiment conducted in this paper.

- One bed can only be used by one patient at a time, but all beds can be allocated between departments.

- Hospital beds are given to patients with the most serious or emergency situation first, with the hierarchy of demand going from the most severe to the least.

- All hospital beds discussed in this paper are of the same type, function, and are used in the same way.

- All arbitrary cases are negligible in the experiment conducted in this paper.

\subsection{Input Variables}

\begin{tabular}{c|c}
\hline Variable Symbol & Variable Name \\
\hline SU & Different States within the United States of America \\
\hline FIS & Patient Inflow in State S \\
\hline FOS & Patient Outflow in State S \\
\hline AS & Average Number of Admissions in State S \\
\hline LOSS & Average Wait Time in State S \\
\hline TS & Population Age (Median) for State \\
\hline TORS & Number of Nurses in Hospitals in Each State \\
\hline PS & Number of Doctors in Hospitals in Each State \\
\hline NH & Number of Other Staff Members in Hospitals in Each State \\
\hline DH & Hospital Departments of Hospitals Across States \\
\hline SH & Maximum Number of Beds Available in Each State \\
\hline HS & Economy/Real GDP of Each State \\
\hline BH & Local Wealth Base in Each State \\
\hline ES & Gini Coefficient of Each State \\
\hline LS & Unemployment Rate of Each State \\
\hline GS & Daily Rotations of Nurses Hospitals in Each State \\
\hline US $\%$ &
\end{tabular}

\subsection{Output (used for decision variable)}

\begin{tabular}{c|c}
\hline SA & Allocation System of Hospital Beds \\
\hline BORS & Bed Occupancy Rate in State S \\
\hline CPIS & Consumer Price Index in Each State \\
\hline OCD & Operating Cost in Each Hospital Department \\
\hline TOCS & Total Operating Cost in Hospitals of State S \\
\hline MHSS & Medicare Hospital Spending Per Patient \\
\hline
\end{tabular}




\begin{tabular}{c|c}
\hline IW & Index of wages and earnings \\
\hline PS & Probability Mass of Observing X admissions of State S \\
\hline
\end{tabular}

\subsection{Parameters}

\begin{tabular}{|c|c|}
\hline Parameter Symbol & Parameter Name \\
\hline$O C N_{i k}$ & Economic Cost of reallocation of $k \in N_{H}$ nurses in state ${ }^{i \in H_{S}}$ \\
\hline$O C D_{i k}$ & Economic Cost of reallocating $k \in D_{H \text { doctors in state }} i \in H_{S}$ \\
\hline$O C S_{i k}$ & $\begin{array}{c}\text { Economic Cost of reallocation of } \begin{array}{c}k \in S_{H} \text { other staff members in state } \\
i \in H_{S}\end{array} \\
\text {. }\end{array}$ \\
\hline$P_{i}$ & The maximum capacity of patients in hospital ${ }^{i \in H_{S}}$ \\
\hline$B P_{i}$ & Maximum number of beds can be allocated in hospital ${ }^{i \in H_{S}}$ \\
\hline$D A_{i k}$ & $\begin{array}{c}\text { Maximum number of } k \in D_{H \text { doctors can be allocated in hospital in }} \\
\text { state } \\
i \in H_{S} \text { without losing function }\end{array}$ \\
\hline$D N_{i}$ & $\begin{array}{l}\text { Maximum number of } \\
\qquad i \in H_{S} \text { without losing function }\end{array}$ \\
\hline$D S_{i}$ & $\begin{array}{c}\text { Maximum number of } k \in S_{H \text { other staff members can be allocated in }} \\
\text { hospital in state } i \in H_{S \text { without losing function }}\end{array}$ \\
\hline$O E_{i}$ & Maximum Full-employment Output of Economy in state $i \in E_{s}$ \\
\hline$M S_{i}$ & Maximum Fund Available in Medicare Sector in state $i \in E_{s}$ \\
\hline$L I_{i}$ & Local Incentive to Invest in Medicare in state ${ }^{i \in L_{S}}$ \\
\hline$T N D_{i}$ & Opportunity/Economic Cost of Training new doctors in state $i \in E_{s}$ \\
\hline$T N N_{i}$ & Opportunity/Economic Cost of Training new nurses in state $i \in E_{s}$ \\
\hline$T N S_{i}$ & $\begin{array}{c}\text { Opportunity/Economic Cost of Training new medicare-affiliated } \\
\text { personnel in country } i \in E_{s}\end{array}$ \\
\hline
\end{tabular}

\subsection{Mathematical Modeling}

The database that we use is medicare.gov, a trustworthy federal government website run and managed by The Centers for Medicare \& Medicaid Services located in Baltimore, MD. To analyze the data we acquired from the database, we will be utilizing microeconomic/macroeconomic tools and mathematical models to predict and find the best suitable solution to the situation. The challenge of the research will be finding an optimal solution that takes in all factors and parties into account, without hurting any affiliated goods and services, or even the entire economy. In the field of this particular research, the best models at hand are Linear Regression/Optimization model, Logistics model, and the Erlang Loss Formula.

\subsection{Objective Function}

In order to optimize the allocation of hospital beds, what we have to do is to minimize the total operating cost (TOCs) in order to make the current allocation system more efficient:

$$
T O C_{S}=\sum_{s} \sum_{k}\left(N_{H} \times O C N_{s k}\right)+\sum_{s} \sum_{k}\left(D_{H} \times O C D_{s k}\right)+\sum_{s} \sum_{k}\left(S_{H} \times O C S_{s k}\right)+\sum_{s} \sum_{j}\left(B_{H} \times O C B_{s j}\right)
$$

Where the corresponding constraints are:

$$
\begin{aligned}
& N_{H} \leq D H_{s k}, \quad S \in S_{U} \\
& D_{H} \leq D A_{s k}, S \in S_{U} \\
& S_{H} \leq D S_{s k}, S \in S_{U}
\end{aligned}
$$

The Relationship between Gini Coefficient, the economic section of our research, and the medical section of our project -- hospital beds is connected through a key economic concept called Lorenz Curve. The method that we used to discover the link between the Gini Coefficient and hospital beds is as follows: 


$$
\mathrm{G}_{\mathrm{S}}=\frac{A_{S}+1-2 \frac{\sum_{s=1}^{A_{S}}\left(A_{S}+1-k\right) \times \operatorname{LOS}_{s k}}{\sum_{s=1}^{A_{S}} \times \operatorname{LOS}_{s k}}}{A_{S}},
$$

in which the Gini Coefficients are already derived from WorldBank.

List of Formulae \& Models:

a) Aging of population and Economy:

- Gini Coefficient

- Lorenz Curve

- Phillips Curve

- Demand \& Supply Curve for the Market in Hospital Beds

b) Reallocation of Hospital Beds based on aging of population and economy:

- Logistics Model for the prediction of future patient flow

- Convolutional Neural Network to help level up the efficiency of Logistics Model by adding artificial intelligence training components into it

- Linear Regression

- For predicting future flows of GDP, GINI Index, and Population Median Age, the autoregressive model based on time series will be:

- GDP: $\mathrm{Es}_{\mathrm{s}}=\beta_{0}+\beta_{1} \mathrm{E}_{\mathrm{s}-1}+\beta_{2} \mathrm{E}_{\mathrm{s}-2}+\beta_{3} \mathrm{E}_{\mathrm{s}-3}+\beta_{4} \mathrm{E}_{\mathrm{s}-4}+\ldots+\beta_{\mathrm{k}} \mathrm{E}_{\mathrm{s}-\mathrm{k}}+\epsilon_{\mathrm{s}}$.

- GINI Index: $\mathrm{G}_{\mathrm{s}}=\beta_{0}+\beta_{1} \mathrm{G}_{\mathrm{s}-1}+\beta_{2} \mathrm{G}_{\mathrm{s}-2}+\beta_{3} \mathrm{G}_{\mathrm{s}-3}+\beta_{4} \mathrm{G}_{\mathrm{s}-4}+\ldots+\beta_{\mathrm{k}} \mathrm{G}_{\mathrm{s}-\mathrm{k}}+\epsilon_{\mathrm{s}}$.

- Population Median Age: $\mathrm{P}_{\mathrm{S}}=\beta_{0}+\beta_{1} \mathrm{P}_{\mathrm{s}-1}+\beta_{2} \mathrm{P}_{\mathrm{s}-2}+\beta_{3} \mathrm{P}_{\mathrm{s}-3}+\beta_{4} \mathrm{P}_{\mathrm{s}-4}+\ldots+\beta_{\mathrm{k}} \mathrm{P}_{\mathrm{s}-\mathrm{k}}+\epsilon \mathrm{s}$.

- Erlang Loss Formula A\&B\&C

- In order to calculate and quantify the load of the hospital system, we need to use the Erlang Loss Formula. The formula will involve the following variables: Patient Inflow PIs, Patient Arrival Rate

- Assumptions: Infinite Population, infinite resources

- Epidemics are very extreme situations in which aren't considered in this experiment

- Hospital Beds -- servers, patients -- subscribers

- Parameters: Patients being asked to stay in hospitals

- Hospital Bed Occupancy Rate

$\circ$ Waiting Time $\rightarrow$ two scenarios: 1 . Waited, derived the bed, 2. Waited, cannot get the bed

- Compare the traffic derived from the formula with the expected value

- Network Furl Model

- Linear Optimization Model

\section{Modeling Software and Programming}

Python 3.5.4 was installed and used as the modeling and programming software in this project and case study. It is a multi-paradigm programming language. Python fully support the programming types of object-oriented programming and structured programming, which satisfy the programming requirement, especially for the neural network model and flow network optimization model.

\section{Case Study}

In this case study, the relationship between the increasing trend for the demand of hospital beds and the increasing cost of healthcare services and the aging of population is investigated. Gini coefficients and Lorenz Curve are used to predict the aging of population, which helps to build up the supply and demand curve of the hospital beds in the long time run. The Erlang Loss Formula is used to analyze the patient flow in the hospitals of the region with the different situations of area and the need for medical care. The Logistic model is used to predict the future outcome of allocation of hospital beds. 
In the next step, the optimization model is proceeded to get the optimal arrangement of hospital bed allocation.

For clarification, the summary tables for the lists of input variables, output variables and parameters for both neural network model and flow network optimization model in this case study are provided separately as below:

\subsection{Neural Network Model}

Input Variable:

\begin{tabular}{c|c}
\hline Variable Symbol & Variable Name \\
\hline SU & Different States within the United States of America \\
\hline PS & Population Age (Median) for State \\
\hline ES & Economy/Real GDP of Each State \\
\hline LS & Local Wealth Base in Each State \\
\hline GS & Gini Coefficient of Each State \\
\hline US\% & Unemployment Rate of Each State \\
\hline
\end{tabular}

Output Variable:

\begin{tabular}{c|c}
\hline CPIS & Consumer Price Index in Each State \\
\hline OCD & Operating Cost in Each Hospital Department \\
\hline IW & Index of wages and earnings \\
\hline
\end{tabular}

Parameters: Index of wages and earnings

\begin{tabular}{c|c}
\hline Parameter Symbol & Parameter Name \\
\hline$O C N_{i k}$ & Economic Cost of reallocation of $k \in N_{H \text { nurses in state }} i \in H_{S}$ \\
\hline$O C D_{i k}$ & Economic Cost of reallocating $k \in D_{H \text { doctors in state }} i \in H_{S}$ \\
\hline$O C S_{i k}$ & Economic Cost of reallocation of $k \in S_{H \text { other staff members in state }}$ \\
$i \in H_{S}$ \\
\hline$O C B_{i j}$ & Economic Cost of rearranging $j \in B_{H}$ hospital beds in state ${ }^{i \in H_{S}}$ \\
\hline
\end{tabular}

\subsection{Network Flow Model minimizing average total cost:}

Input Variable:

\begin{tabular}{|c|c|}
\hline Variable Symbol & Variable Name \\
\hline SU & Different States within the United States of America \\
\hline FIS & Patient Inflow in State S \\
\hline FOS & Patient Outflow in State S \\
\hline AS & Average Number of Admissions in State $\mathrm{S}$ \\
\hline $\mathrm{NH}$ & Number of Nurses in Hospitals in Each State \\
\hline $\mathrm{DH}$ & Number of Doctors in Hospitals in Each State \\
\hline $\mathrm{SH}$ & Number of Other Staff Members in Hospitals in Each State \\
\hline HS & Hospital Departments of Hospitals Across States \\
\hline $\mathrm{BH}$ & Maximum Number of Beds Available in Each State \\
\hline RH & Daily Rotations of Nurses Hospitals in Each State \\
\hline
\end{tabular}

Output Variable:

\begin{tabular}{c|c}
\hline SA & Allocation System of Hospital Beds \\
\hline TOCS & Total Operating Cost (Or Average Total Cost) in Hospitals of State S \\
\hline MHSS & Medicare Hospital Spending Per Patient \\
\hline PS & Probability Mass of Observing X admissions of State S \\
\hline
\end{tabular}

Parameters:

\begin{tabular}{|c|c|}
\hline Parameter Symbol & Parameter Name \\
\hline$O C N_{i k}$ & Economic Cost of reallocation of $k \in N_{H \text { nurses in state }} i \in H_{S}$ \\
\hline$O C D_{i k}$ & Economic Cost of reallocating $k \in D_{H \text { doctors in state }} i \in H_{S}$ \\
\hline$O C S_{i k}$ & $\begin{array}{l}\text { Economic Cost of reallocation of } k \in S_{H \text { other staff members in state }} \\
\qquad i \in H_{S}\end{array}$ \\
\hline$O C B_{i j}$ & Economic Cost of rearranging $j \in B_{H}$ hospital beds in state $i \in H_{S}$ \\
\hline$P_{i}$ & The maximum capacity of patients in hospital $i \in H_{S}$ \\
\hline$B P_{i}$ & Maximum number of beds can be allocated in hospital $i \in H_{S}$ \\
\hline$D A_{i k}$ & $\begin{array}{c}\text { Maximum number of } k \in D_{H \text { doctors can be allocated in hospital in }} \\
\text { state } i \in H_{S \text { without losing function }}\end{array}$ \\
\hline
\end{tabular}




\begin{tabular}{|c|c|}
\hline$D N_{i}$ & $\begin{array}{l}\text { Maximum number of } k \in N_{H \text { nurses can be allocated in hospital in state }} \\
\qquad i \in H_{S \text { without losing function }}\end{array}$ \\
\hline$D S_{i}$ & 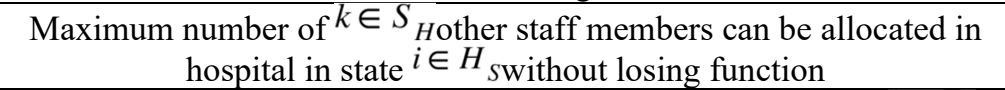 \\
\hline$T N D_{i}$ & Opportunity/Economic Cost of Training new doctors in state $i \in E_{s}$ \\
\hline$T N N_{i}$ & Opportunity/Economic Cost of Training new nurses in state $i \in E_{s}$ \\
\hline$T N S_{i_{-}}$ & $\begin{array}{c}\text { Opportunity/Economic Cost of Training new medicare-affiliated } \\
\text { personnel in country } i \in E_{s}\end{array}$ \\
\hline
\end{tabular}

For the input variables and parameters, as it can be seen from the below Figure 1, the trend of the median age of main UN regions is generally sloping upward, meaning that the median age is going to increase over time. Of the set of six sub-graphs, the first shows that the proportion of old-age is augmenting as time goes on, which indicates that the overall population is gradually aging. It is a tumor resting inside the heart of this very world, that needs to be removed.

\section{Overview main UN regions}
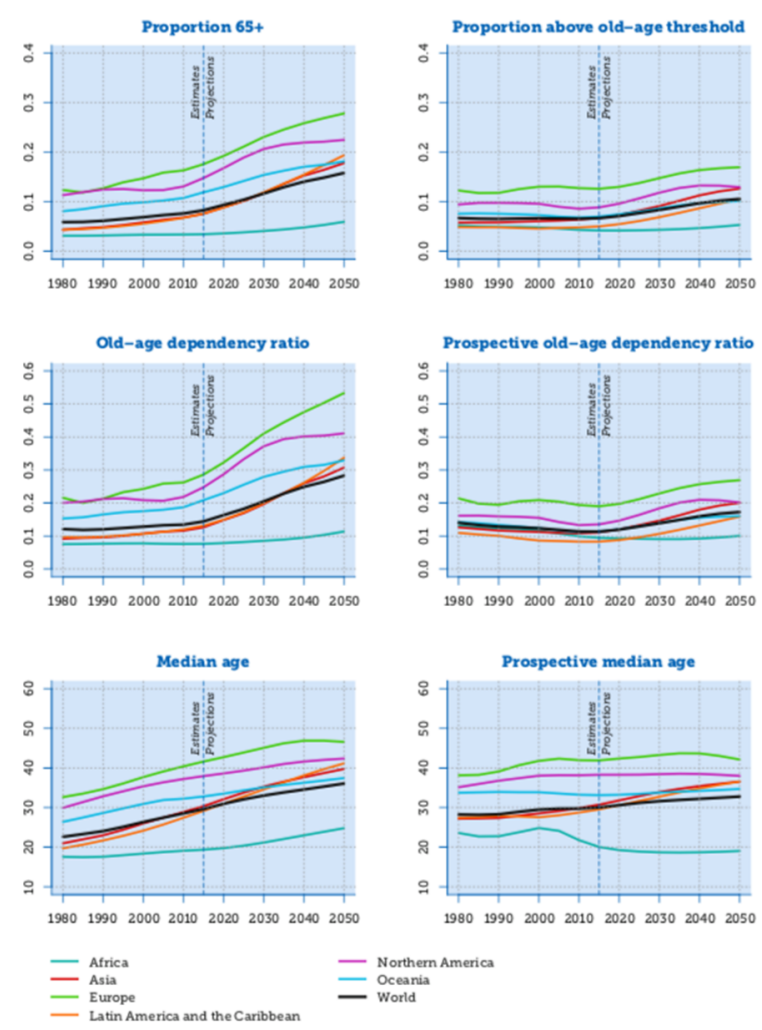

Fig. 1. Aging Demographics Data Sheet 2018 with the Overview of Main UN regions (Aging Demographics Data Sheet, 2018) ([1])

From this statistics graph of Figure 2, we can see that out of all the states in the United States of America, the following states are undergoing an aging population more severe of others (in alphabetical order): Connecticut, Florida, Maine, New Hampshire, Pennsylvania, Vermont, West Virginia. Further in the research, we will see more indicators that will demonstrate the negative effects of aging population. On the other hand, there are also some states that have exceptionally "young" population, such as (in alphabetical order): Alaska, California, District of Columbia, Georgia, Idaho, Louisiana, Mississippi, Nebraska, Nevada, New Mexico, New Dakota, Oklahoma, Utah, and Washington. Deeper into the paper, we will explore whether this is a good sign for the hospital bed system and the economy. 

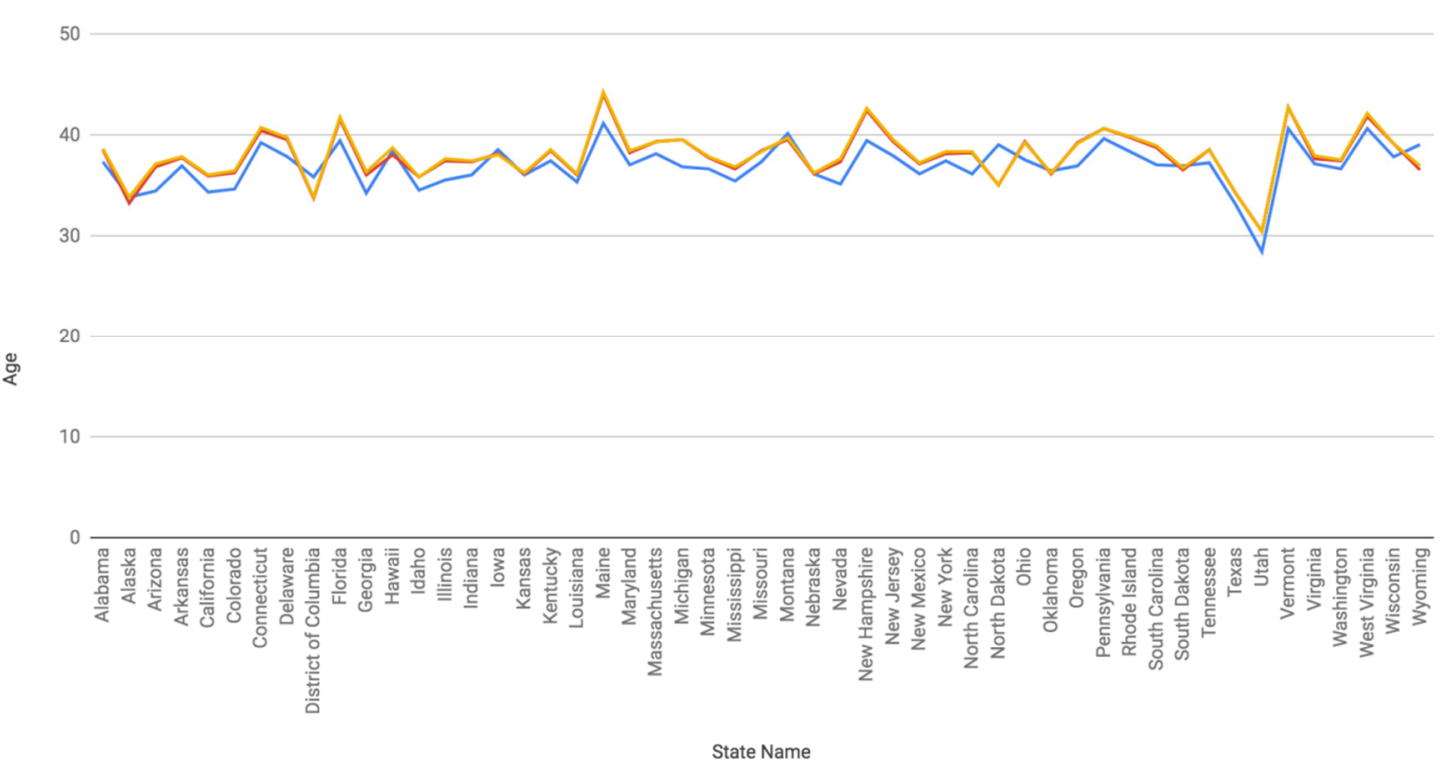

Fig. 2. Comparison Chart of the Average Age in Each USA State (Census.Gov, 2015) ([2])

\subsection{Economy Section of Research for the Analyzing of GDP}

The below summary table (Table 1. Summary Table of GDP by States from 2000 to 2018) and figure (Figure 3. Gini Coefficient by all USA State from 2006 to 2014) show that there's a strong correlation between time and GDP growth, meaning that most of the states, if not all, have achieved certain real GDP growth (economic growth). According to the macroeconomic concept of Purchasing Power Parity, people's purchasing power in each state levitated as a result of increasing real GDP. The effect of that, assuming Keynesian thinkings apply, will bring the state economy to a whole new level where people's life standard is significantly higher than they were a couple of years ago.

Table 1. Summary Table of GDP by States from 2000 to 2018

\begin{tabular}{|c|c|c|c|c|}
\hline 2000 & 2001 & 2002 & 2003 & 2004 \\
\hline : 17205 & Min. : 18661 & Min. : 19116 & Min. : 21028 & Min. : 22666 \\
\hline 1st Qu.: 50229 & 1st Qu.: 51308 & 1st Qu.: 53367 & 1st Qu.: 57137 & 1st Qu.: 61934 \\
\hline Median : 117258 & Median : 119301 & Median : 124160 & Median : 130337 & Median : 136238 \\
\hline Mean : 199734 & Mean : 206187 & Mean : 213114 & Mean : 223245 & Mean : 237995 \\
\hline 3rd Qu.: 252359 & 3rd Qu.: 261714 & 3rd Qu.: 270732 & 3rd Qu.: 283790 & 3rd Qu.: 299076 \\
\hline $\begin{array}{l}\text { Max. } \\
2005\end{array}$ & Max. $\underbrace{: 1384111}_{2006}$ & $\begin{array}{c}\text { Max. } \\
2007\end{array}$ & $\begin{array}{c}\text { Max. } \\
2008\end{array}$ & Max. ${ }_{2009}^{: 1632217}$ \\
\hline $\begin{array}{ll}\text { Min. }: & 23509 \\
\text { 1st Qu.: } & 66176\end{array}$ & $\begin{array}{l}\text { Min. : } 24310 \\
\text { 1st Qu.: } 69896\end{array}$ & $\begin{array}{ll}\text { Min. } & 24697 \\
\text { 1st Qu.: } & 72903\end{array}$ & $\begin{array}{ll}\text { Min. } \quad: & 25678 \\
\text { 1st Qu.: } & 75294\end{array}$ & $\begin{array}{ll}\text { Min. }: & 25868 \\
\text { 1st Qu.: } & 73855\end{array}$ \\
\hline Median : 143663 & Median : 155153 & Median : 161512 & Median : 165189 & Median : 160641 \\
\hline Mean : 254065 & Mean : 269254 & Mean : 281683 & Mean : 286695 & Mean : 281388 \\
\hline 3rd Qu.: 320843 & 3rd Qu.: 339217 & 3rd Qu.: 363160 & 3rd Qu.: 370866 & 3rd Qu.: 359612 \\
\hline $\begin{array}{l}\text { Max. } \\
2010\end{array}$ & $\begin{array}{c}\text { Max. } \quad: 1874737 \\
2011\end{array}$ & $\begin{array}{l}\text { Max. } \\
2012\end{array}$ & $\begin{array}{c}\text { Max. } \quad: 1990678 \\
2013\end{array}$ & $\begin{array}{c}\text { Max. } \quad: 1920062 \\
2014\end{array}$ \\
\hline $\begin{array}{ll}\text { Min. }: & 27108 \\
\text { 1st Qu.: } & 76093\end{array}$ & $\begin{array}{ll}\text { Min. }: & 28135 \\
\text { 1st Qu.: } & 78554\end{array}$ & $\begin{array}{ll}\text { Min. } \quad & 28887 \\
\text { 1st Qu.: } & 80592\end{array}$ & $\begin{array}{lll}\text { Min. } \quad: & 29099 \\
\text { 1st Qu.: } & 82100\end{array}$ & $\begin{array}{ll}\text { Min. }: & 29714 \\
\text { 1st Qu.: } & 85234\end{array}$ \\
\hline Median : 164606 & Median : 170621 & Median : 176302 & Median : 183015 & Median : 194060 \\
\hline Mean : 291924 & Mean : 302576 & Mean : 315368 & Mean : 326893 & Mean : 341331 \\
\hline 3rd Qu.: 376089 & 3rd Qu.: 390322 & 3rd Qu.: 409860 & 3rd Qu.: 426031 & 3rd Qu.: 445703 \\
\hline $\begin{array}{l}\text { Max. }: 1974614 \\
2015\end{array}$ & $\begin{array}{c}\text { Max. }: 2050057 \\
2016\end{array}$ & $\begin{array}{c}\text { Max. }: 2144497 \\
2017\end{array}$ & $\begin{array}{c}\text { Max. }: 2262771 \\
2018\end{array}$ & Max. $: 2396552$ \\
\hline $\begin{array}{ll}\text { Min. }: & 30709 \\
\text { 1st Qu.: } & 86829\end{array}$ & $\begin{array}{ll}\text { Min. } & 31635 \\
\text { 1st Qu.: } & 88435\end{array}$ & $\begin{array}{ll}\text { Min. } \quad & 32623 \\
\text { 1st Qu.: } & 91641\end{array}$ & $\begin{array}{ll}\text { Min. } \quad & 33725 \\
\text { 1st Qu.: } & 95731\end{array}$ & \\
\hline Median : 203323 & Median : 212675 & Median : 221896 & Median : 230354 & \\
\hline Mean : 355046 & Mean : 364594 & Mean : 379845 & Mean : 399713 & \\
\hline 3rd Qu.: 472285 & 3rd Qu.: 491563 & 3rd Qu.: 508135 & 3rd Qu.: 531229 & \\
\hline Max. $: 2558171$ & Max. $: 2663396$ & Max. $: 2809922$ & Max. $: 2968118$ & \\
\hline
\end{tabular}


GDPState[, 8:16]
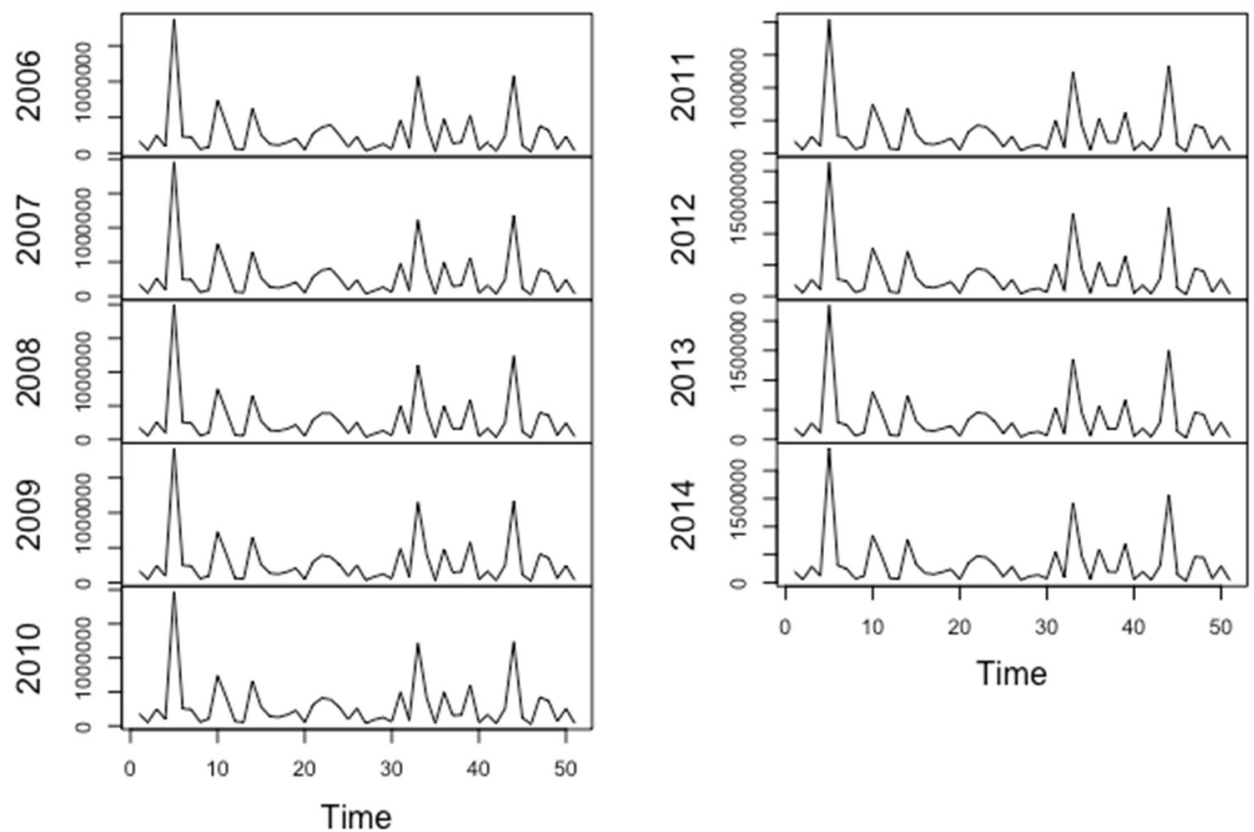

Fig. 3. Gini Coefficient by all USA States from 2006 to 2014

\subsection{Gini Coefficient}

Analysis Graph:

Gini Coefficient by State in 2000

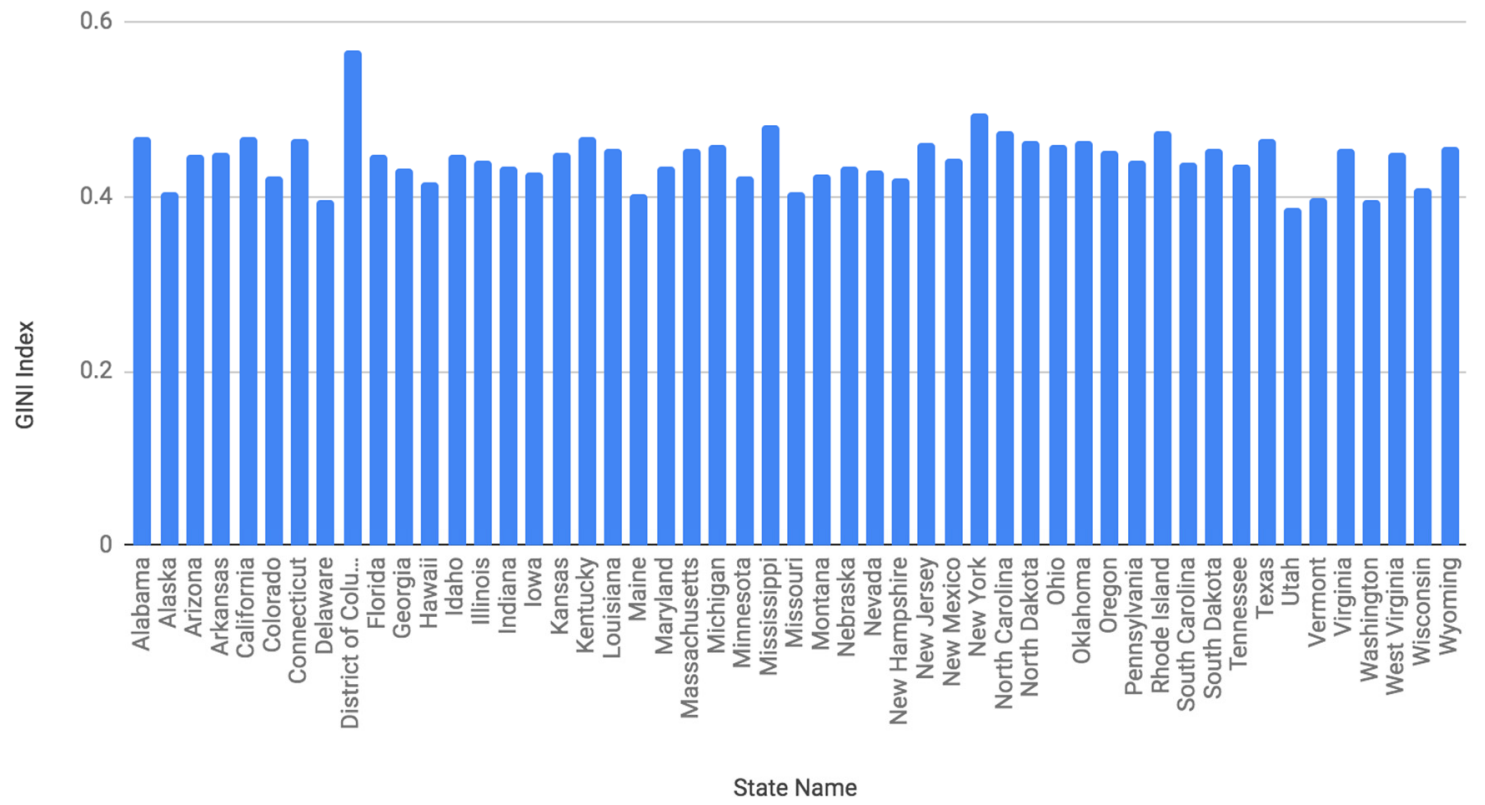

Fig. 4. Gini Coefficient by all USA States in 2000

(https://www.americashealthrankings.org/explore/annual/measure/gini/state/ALL) 


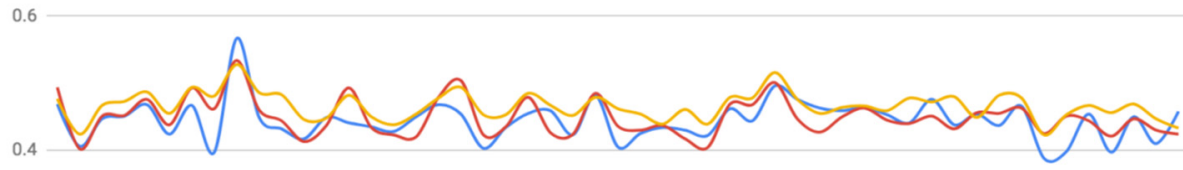

를

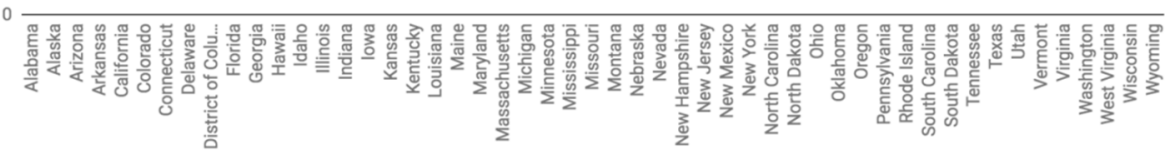

State Name

Fig. 5. Gini Coefficient by all USA States in 2000, 2009 and

2018(https://www.americashealthrankings.org/explore/annual/measure/gini/state/ALL)

Histogram of GINI Index: 2000

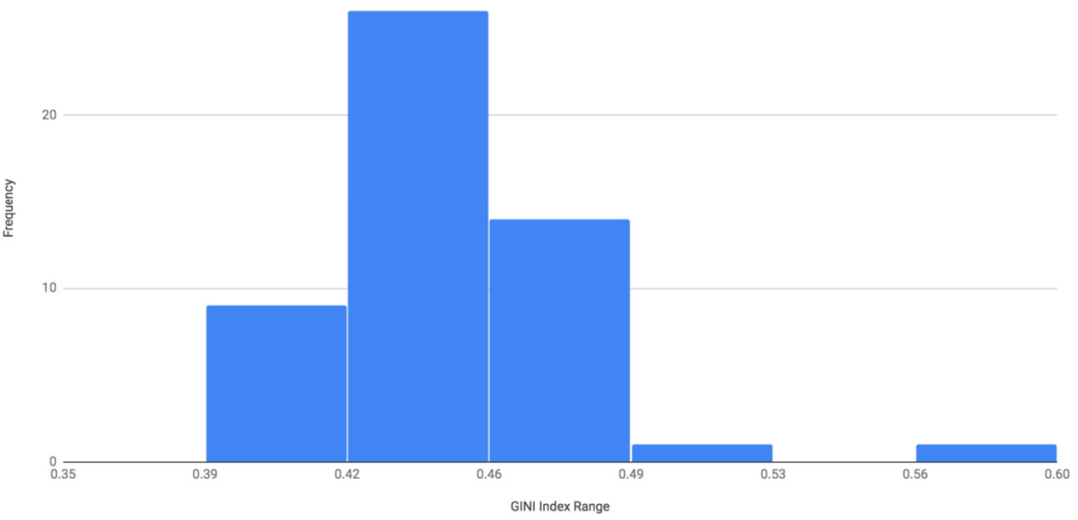

Fig. 6. Histogram of GINI Index in 2000

(https://www.americashealthrankings.org/explore/annual/measure/gini/state/ALL)

Histogram of GINI Index: 2009

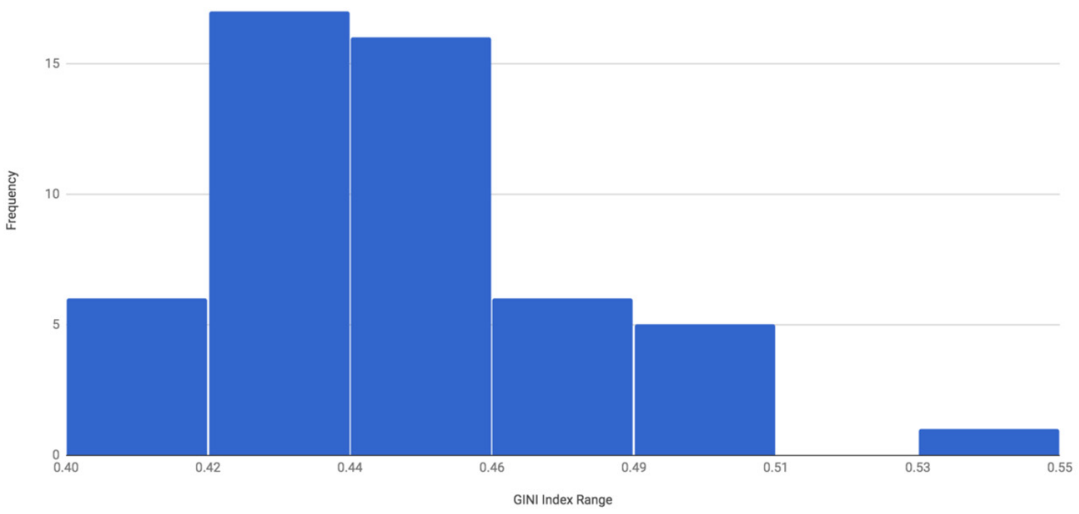

Fig. 7. Histogram of GINI Index in 2009

(https://www.americashealthrankings.org/explore/annual/measure/gini/state/ALL) 


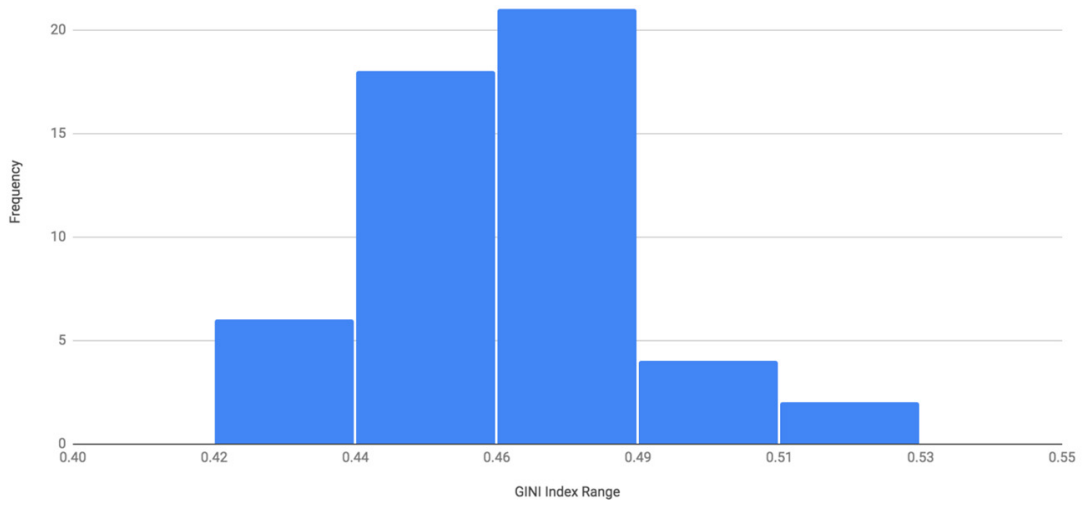

Fig. 8. Histogram of GINI Index in

2018(https://www.americashealthrankings.org/explore/annual/measure/gini/state/ALL)

Combining the above histograms (Figure 4 to Figure 8), we can observe a general trend of the overall Gini Index by state. In 2000, where an economic boom is circulating around the states, most of the states possess a GINI index around 0.42 0.45.

\subsection{Project Bed Value Formula proposed by National Health Service (NHS):}

$$
\text { Beds }=\text { Activity } \times \frac{(\operatorname{LOS}+\mathrm{TOI})}{365}
$$

Where LOS $=$ Length of Stay, TOI = Turn Over Interval, Activity

According to historic data distribution (Figure 9 and Figure 10), it can be seen that the average number of patient arrivals in a typical ICU unit of a hospital is around 3 patients in every 2 hours, which equalizes 36 patients in every 24 hours. From that, we can conclude that the average patient arrival rate is 1.5 patients per hour.

\section{Bed Occupancy Rate By State}

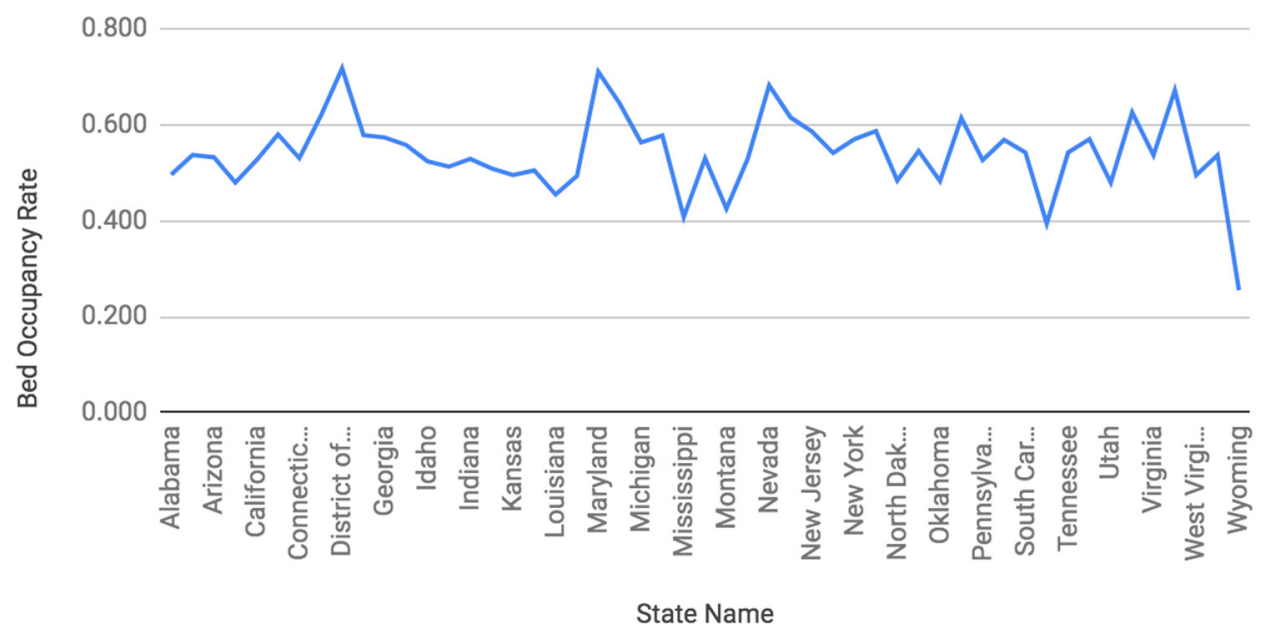

Fig. 9. Bed Occupancy Rate by State in $2018([3,4])$ 


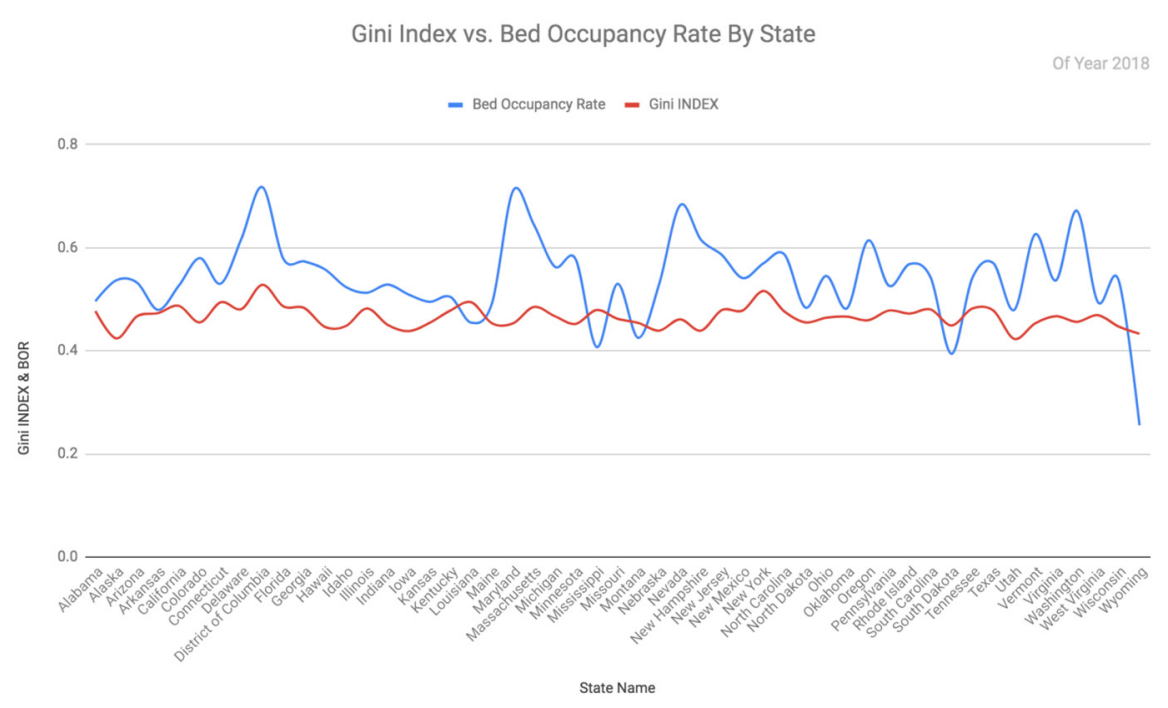

Fig. 10. Comparison Chart between Gini Index and Bed Occopancy Rate by State $([3,4])$

Reference Websites: [3, 4].

According to historic data distribution, we've seen that the average number of patient arrivals in a typical ICU unit of a hospital is around 3 patients every 2 hours, which equalizes 36 patients every 24 hours. From that, we can conclude that the average patient arrival rate is 1.5 patients per hour.

Reference Websites: [3, 4].

The Erlang Blocking Probabilities of a Patient Entering a Hospital under different number of servers can be seen in below Figure 14.

\subsection{Poisson Distribution Model:}

The Poisson distribution model in this study measures the probability of having $\mathrm{x}$ admissions of hospital in each state through using the mean admissions $\left(\lambda_{S}\right)$ of hospital by state:

$$
P_{S}=\frac{\lambda_{S}{ }^{x} \times e^{-\lambda_{S}}}{x !}
$$

Integrating data and executing the model, we find, for example:

Due to high amounts of graphs generated, the following states are considered representatives of other states in the United States of America because: among all fifty states, the state has an extremely above-the-average admissions, the state has an approximately average admissions, the state has a significantly below-the-average admissions.

Poisson Distribution of Number of Admissions

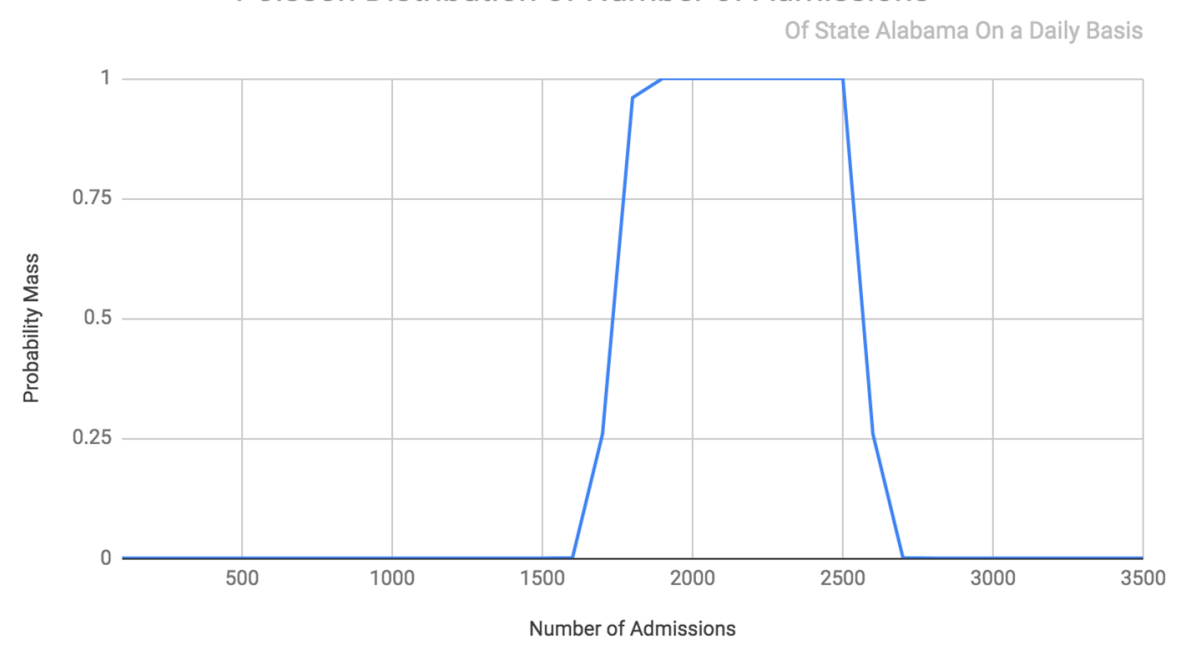

Fig. 11. Poisson Distribution of Number of Admission of State of Alabama on a Daily Basis 


\section{Poisson Distribution of Number of Admissions}

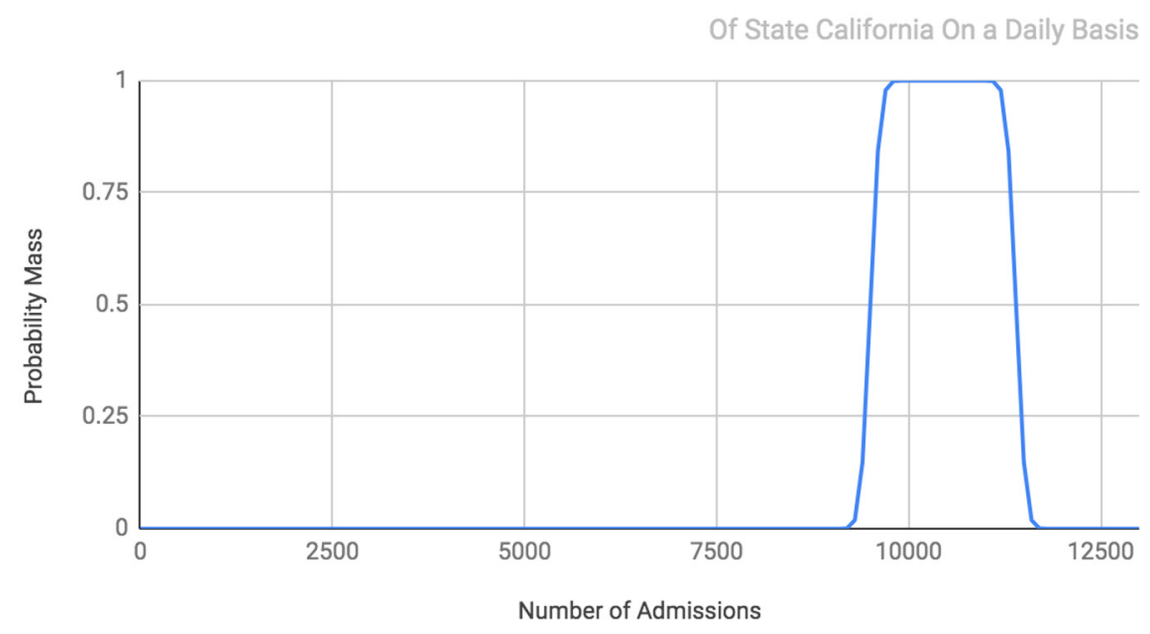

Fig. 12. Poisson Distribution of Number of Admission of State of California on a Daily Basis

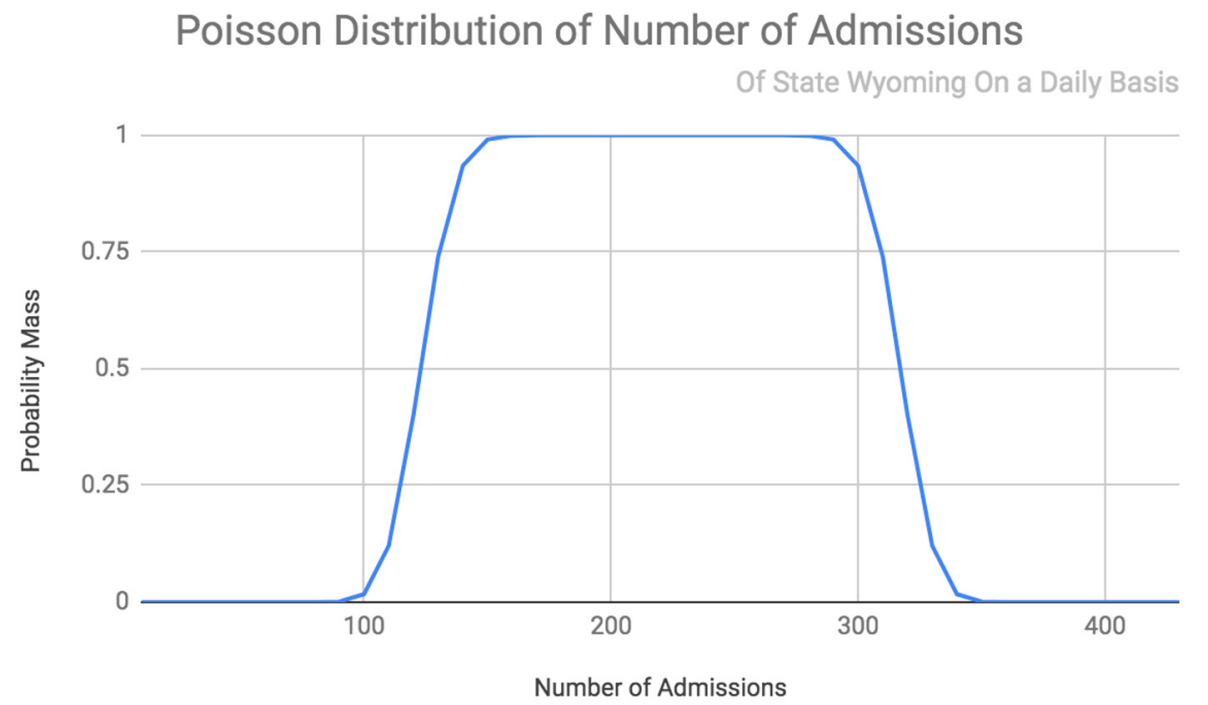

Fig. 13. Poisson Distribution of Number of Admission of State of Wyoming on a Daily Basis

Due to the fact that a significant amount of patients require, below values are used for the function of Erlang loss, which can be seen in the below Table. The minimum value of bed occupancy rate is in the state of Wyoming whose bed occupancy rate is 0.255 ; the maximum value of bed occupancy rate is in the District of Columbia whose bed occupancy rate is 0.717 ; the bed occupancy rate of New Mexico is closest to average with the value of 0.541 .

In those less developed areas/states, it is shown that average patient visits per hour is significantly higher than those more developed. To make matters worse, those hospitals in less developed areas tend to have longer wait time.

Table 2. Hospital bed summary for all the States in USA

\begin{tabular}{cccc}
\hline State Name & $\begin{array}{c}\text { Bed } \\
\text { Occupancy } \\
\text { Rate }\end{array}$ & $\begin{array}{c}\text { Average Total Cost of } \\
\text { Operation (dollars) for the } \\
\text { Operation of Hospital Beds } \\
\text { Before Optimization }\end{array}$ & $\begin{array}{c}\text { Average Total Cost } \\
\text { (dollars) For the Operation } \\
\text { of Hospital Beds After } \\
\text { Optimization }\end{array}$ \\
\hline Alabama & 0.496 & 58879073 & 54168747 \\
Alaska & 0.537 & 5203676 & 4865437 \\
Arizona & 0.532 & 76973790 & 73125101 \\
Arkansas & 0.479 & 26221776 & 24648469
\end{tabular}




\begin{tabular}{|c|c|c|c|}
\hline California & 0.526 & 429446770 & 416563367 \\
\hline Colorado & 0.58 & 63807390 & 58702799 \\
\hline Connecticut & 0.53 & 37809922 & 35919426 \\
\hline Delaware & 0.618 & 7242217 & 6800442 \\
\hline District of Columbia & 0.717 & 12057165 & 10128019 \\
\hline Florida & 0.578 & 317798920 & 286019028 \\
\hline Georgia & 0.573 & 100089929 & 89080037 \\
\hline Hawaii & 0.558 & 7785550 & 7240562 \\
\hline Idaho & 0.524 & 12093793 & 10521600 \\
\hline Illinois & 0.512 & 143676465 & 129308819 \\
\hline Indiana & 0.528 & 78714176 & 73991325 \\
\hline Iowa & 0.509 & 31789578 & 29246412 \\
\hline Kansas & 0.495 & 31789578 & 30517995 \\
\hline Kentucky & 0.505 & 56632631 & 53574469 \\
\hline Louisiana & 0.454 & 54387626 & 48404987 \\
\hline Maine & 0.493 & 10890862 & 9583959 \\
\hline Maryland & 0.71 & 18592438 & 17272375 \\
\hline Massachusetts & 0.644 & 65190065 & 63886264 \\
\hline Michigan & 0.563 & 91688720 & 87104284 \\
\hline Minnesota & 0.577 & 44048408 & 40084051 \\
\hline Mississippi & 0.407 & 34477291 & 31029562 \\
\hline Missouri & 0.53 & 71510458 & 66647747 \\
\hline Montana & 0.425 & 7218737 & 6135926 \\
\hline Nebraska & 0.529 & 13688823 & 12183052 \\
\hline Nevada & 0.682 & 43301063 & 40269989 \\
\hline New Hampshire & 0.615 & 12484187 & 10861243 \\
\hline New Jersey & 0.586 & 123991272 & 116923769 \\
\hline New Mexico & 0.541 & 17358825 & 15970119 \\
\hline New York & 0.57 & 236602658 & 228321565 \\
\hline North Carolina & 0.587 & 97970172 & 93071663 \\
\hline North Dakota & 0.484 & 8225841 & 7403257 \\
\hline Ohio & 0.545 & 141320494 & 131428059 \\
\hline Oklahoma & 0.483 & 44334858 & 38127978 \\
\hline Oregon & 0.614 & 27243728 & 25418398 \\
\hline Pennsylvania & 0.526 & 197599002 & 185743062 \\
\hline Rhode Island & 0.568 & 9837614 & 9345733 \\
\hline South Carolina & 0.542 & 56901031 & 51779938 \\
\hline South Dakota & 0.394 & 10990938 & 9924817 \\
\hline Tennessee & 0.542 & 81319711 & 74163576 \\
\hline Texas & 0.57 & 316275251 & 299512663 \\
\hline Utah & 0.479 & 18852122 & 17532473 \\
\hline Vermont & 0.626 & 4341232 & 3863696 \\
\hline Virginia & 0.536 & 79435741 & 72127653 \\
\hline Washington & 0.672 & 62824835 & 58112972 \\
\hline West Virginia & 0.495 & 18528528 & 17250060 \\
\hline Wisconsin & 0.537 & 52700867 & 48484798 \\
\hline Wyoming & 0.255 & 2847221 & 2519791 \\
\hline
\end{tabular}




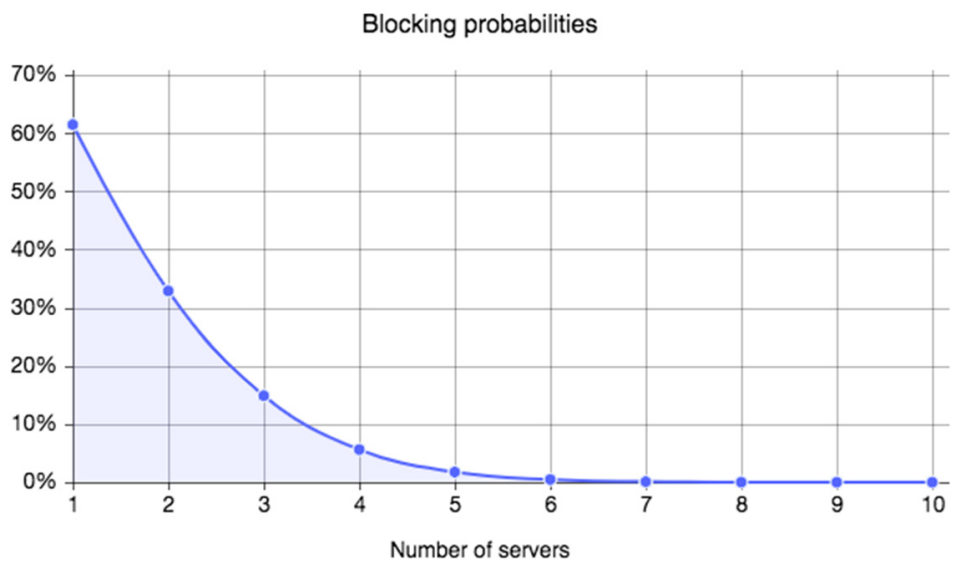

Fig. 14. Erlang Blocking Probabilities of a Patient Entering a Hospital under different number of servers

Network Flow model is used in the evaluation to minimize average total cost of operating hospital beds. From the calculations and graphic representation of GINI Coefficient and the models, we can see that the current hospital bed management system is, to some extent, somewhat efficient. However, this only applies to those states where the GDP is comparatively high, and the GINI Coefficient/Lorenz Curve is low and stable. In the states where there is a large gap between the rich and the poor like the District of Columbia, the current system that is running in the medical section of the government isn't at its optimum capacity.

The average total cost (dollars) for the operation of hospital beds in each state before and after optimization have been presented in Table 3. The comparison chart has also been provided in Figure 15. The histogram charts for the average total cost of operation (dollars) for the operation of hospital beds for all the states in USA before and after the optimization are presented in Figure 16 and Figure 17 respectively.

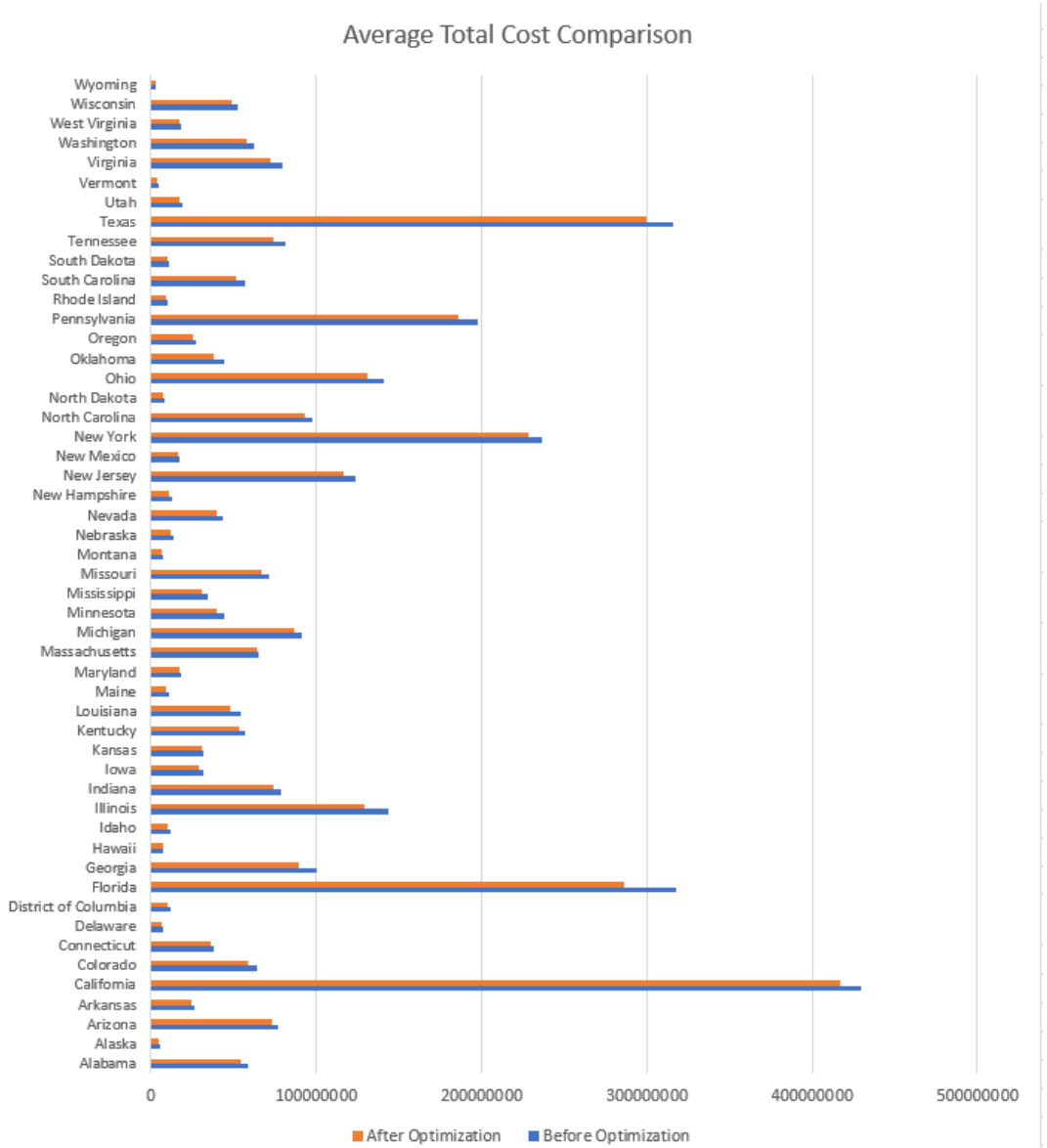

Fig. 15. Comparison Chart for Average Total Cost for the Operation of Hospitals Beds in Each State Before and After the Optimization 


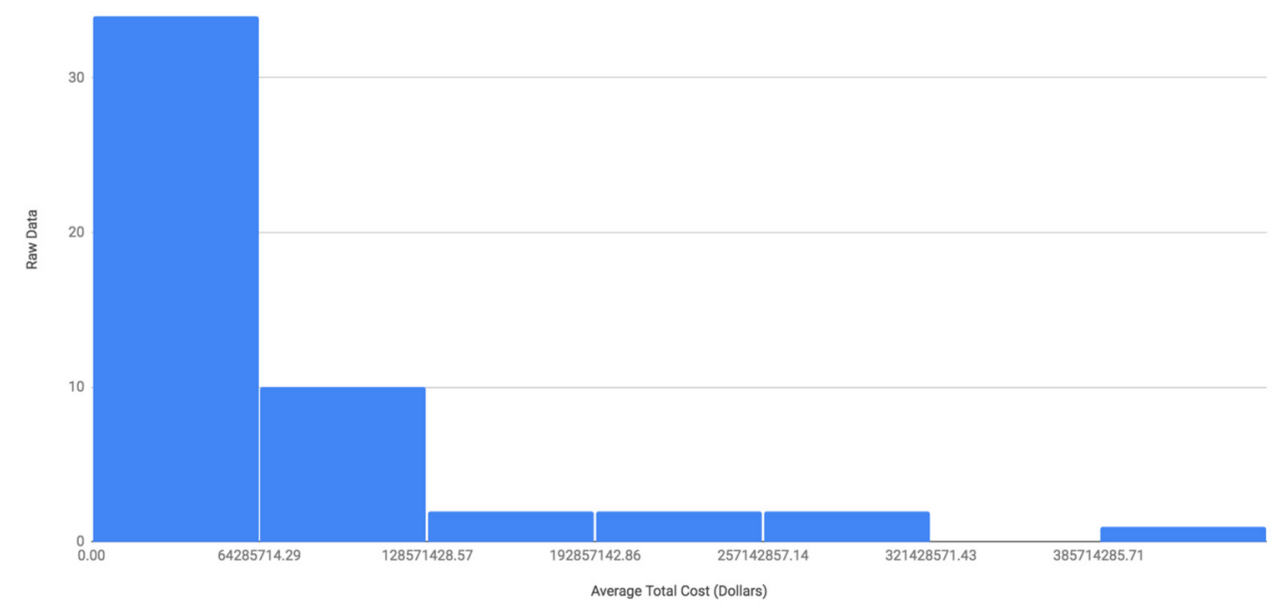

Fig. 16. Histogram Charts for the Average Total Cost of Operation (Dollars) for the Operation of Hospital Beds for All the States in USA Before the Optimization

Histogram of Data After Optimization

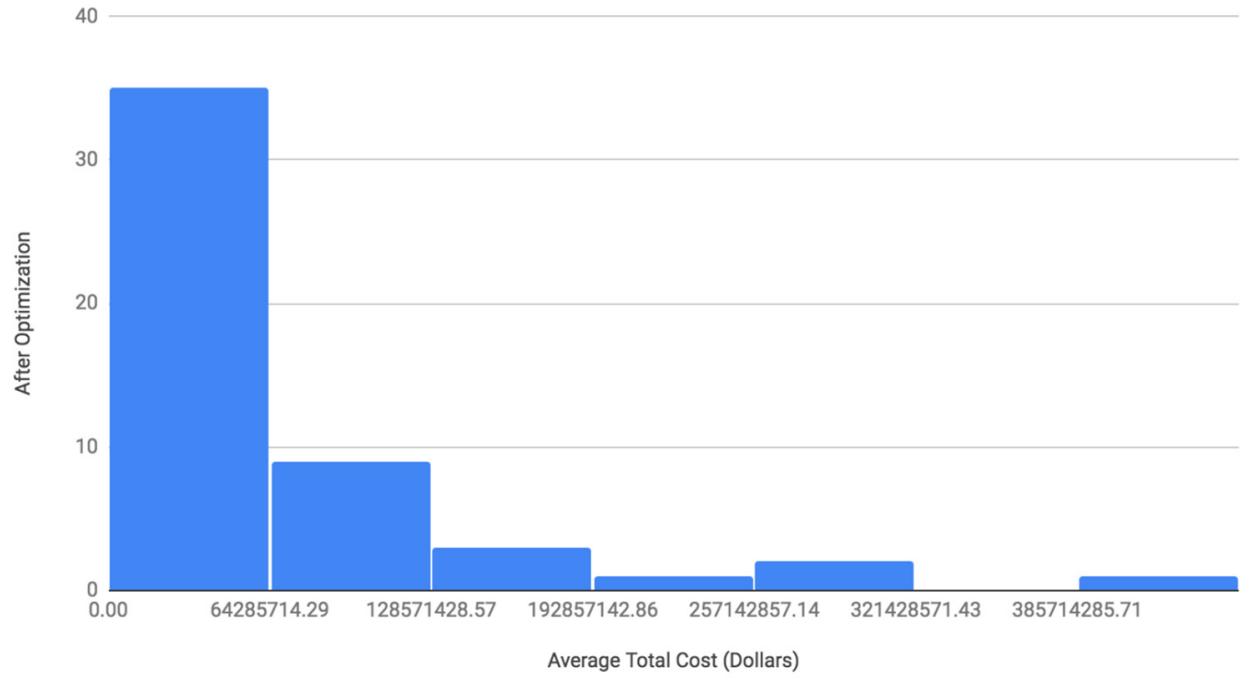

Fig. 17. Histogram Charts for the Average Total Cost of Operation (Dollars) for the Operation of Hospital Beds for All the States in USA After the Optimization

The network flow model suggests that the average total cost of running hospital beds can be reduced up to $5 \%$ in those more developed areas/states while the reduction is even higher, hitting $15 \%$ in some less developed areas/states, once the hospitals get rid of redundancies. Through the effects of expansionary fiscal policies and monetary policies conducted by both the federal government and the Fed (central bank), we will be able to make available more funds that can be allocated to the medical sector, and, in the meantime, reducing the average total cost that places a huge burden on certain hospitals.

A higher GINI coefficient will result in a more unstable Lorenz Curve. Through further research presented in this report, we find out that a higher GINI Index also means a wider Poisson Distribution, higher bed/inpatient days, patient arrival rate, bed occupancy rates, emergency room wait time, bed turnover ratio, etc., with less beds per capita actually available for citizens of the state. 


\section{Conclusion}

In this study, the relationship between the current increasing trend for the demand of hospital beds and the increasing cost of healthcare services and the aging of population is evaluated, which will help the hospitals need to integrate the resource management and hospital bed allocation. ini coefficients and Lorenz Curve are used to predict the aging of population, which helps to build up the supply and demand curve of the hospital beds in the long time run. The Erlang Loss Formula is used to analyze the patient flow in the hospitals of the region with the different situations of area and the need for medical care. The Logistic model is used to predict the future outcome of allocation of hospital beds. In the next step, the optimization model is proceeded to get the optimal arrangement of hospital bed allocation. The Network Flow model is used in the evaluation to minimize average total cost of operating hospital beds.

Based on the modeling result, it can be seen that the current hospital bed management system is, to some extent, somewhat efficient. However, this only applies to those states where the GDP is comparatively high and the GINI Coefficient/Lorenz Curve is low and stable. In the states where there is a large gap between the rich and the poor like the District of Columbia, the current system that is running in the medical section of the government isn't at its optimum capacity. The network flow model suggests that the average total cost of running hospital beds can be reduced up to $5 \%$ in those more developed areas/states while the reduction is even higher, hitting $15 \%$ in some less developed areas/states, once the hospitals get rid of redundancies. Through the effects of expansionary fiscal policies and monetary policies conducted by both the federal government and the Fed (central bank), we will be able to make available more funds that can be allocated to the medical sector, and, in the meantime, reducing the average total cost that places a huge burden on certain hospitals. A higher GINI coefficient will result in a more unstable Lorenz Curve. Through further research presented in this report, we find out that a higher GINI Index also means a wider Poisson Distribution, higher bed/inpatient days, patient arrival rate, bed occupancy rates, emergency room wait time, bed turnover ratio, etc., with less beds per capita actually available for citizens of the state.

\section{References}

[1] Aging Demographics Data Sheet, 2018. http://www.iiasa.ac.at/web/home/research/ researchPrograms/WorldPopulation/PublicationsMediaCoverage/ModelsData/AgingDemDataS heet2018_web.pdf.

[2] Census.Gov, 2015. https://factfinder.census.gov/faces/nav/jsf/pages/community facts.xhtml?src=bkmk, https://www.denverpost.com/2015/10/08/chart-compare-the-averageage-in-each-u-s-state-2005-2014/.

[3] American Hospital Association. https://www.aha.org/statistics/fast-facts-us-hospitals.

[4] Beckers Hospital Review. https://www.beckershospitalreview.com/patient-flow/state-by-statebreakdown-of-hospital-admission-rates.html.

[5] Ellis, G., Whitehead, M. A., Robinson, D., O’Neill, D., \& Langhorne, P. (2011). Comprehensive geriatric assessment for older adults admitted to hospital: meta-analysis of randomised controlled trials. Bmj, 343, d6553.

[6] Freitas, E. E. C., \& Schramm, F. R. (2009). The morality of allocating resources to the elderly care in intensive care unit. Revista Brasileira de terapia intensiva, 21(4), pp. 432-436.

[7] Gorunescu, F., McClean, S. I., \& Millard, P. H. (2002). Using a queueing model to help plan bed allocation in a department of geriatric medicine. Health care management science, 5(4), pp. $307-$ 312. 
[8] Nguyen, J. M., Six, P., Antonioli, D., Glemain, P., Potel, G., Lombrail, P., \& Le Beux, P. (2005). A simple method to optimize hospital beds capacity. International journal of medical informatics, 74(1), pp. 39-49.

[9] Suppapitnarm, N., \& Pongpirul, K. (2018). Model for allocation of medical specialists in a hospital network. Journal of healthcare leadership, 10, 45.

[10]Tanner, R., \& Bercaw, L. (2005). Long-term care: long-term care insurance--2005. End of Year Issue Brief. Issue brief (Health Policy Tracking Service), pp.1-10. 